\title{
Formação para o SUS: a trajetória de adesáo de um curso de terapia ocupacional às políticas indutoras de mudança curricular Pró e PET- Saúde ${ }^{1,2}$
}

\author{
Training for SUS: the adhesion trajectory of a course on occupational \\ therapy to the inducing policies of curricular change Pró and PET-Saude \\ Carolina Maria do Carmo Alonso ${ }^{\mathrm{a}}$ (D), Ana Paula Martins Cazeiro ${ }^{\mathrm{ab}}$ (D), Marcia Cabral da Costa ${ }^{\mathrm{a}}$ (D), \\ Renata Caruso Mecca $^{a}$ (D)
}

${ }^{a}$ Departamento de Terapia Ocupacional, Universidade Federal do Rio de Janeiro - UFRJ, Rio de Janeiro, RJ, Brasil.

${ }^{b}$ Departamento de Fundamentos da Educação, Universidade Federal do Ceará - UFC, Fortaleza, CE, Brasil.

Como citar: Alonso, C. M. C., Cazeiro, A. P. M., Costa, M. C., \& Mecca, R. C. (2021). Formação para o SUS: a trajetória de adesão de um curso de terapia ocupacional às políticas indutoras de mudança curricular pró e PETSaúde. Cadernos Brasileiros de Terapia Ocupacional, 29, e2771. https://doi.org/10.1590/2526-8910.ctoRE2094

\begin{abstract}
Resumo
Tendo por base a relevância das políticas indutoras da formação para, com e no Sistema Único de Saúde (SUS), este artigo apresenta a experiência da participação do Curso de Graduação em Terapia Ocupacional da Universidade Federal do Rio de Janeiro no Pró-Saúde e no PET-Saúde, bem como indica as perspectivas e desafios que ainda se configuram. Trata-se de um relato de experiência a respeito de como, juntamente com outros cursos da universidade, o curso de terapia ocupacional se lançou ao desafio de rever sua matriz curricular, criando metodologias de ensino e aprendizagem que favorecessem uma formação profissional eticamente compromissada com o SUS e que reconhecessem o papel estratégico da Atenção Básica à Saúde (ABS) nos modos de pensar e agir em saúde. Nesse contexto, foi eleita uma unidade básica de saúde no entorno da Universidade que passou a receber estudantes de seis disciplinas obrigatórias remodeladas para promover maior integração ensinoserviço. Também foram desenvolvidas açốes de extensão e projetos de pesquisa abarcando populaçóes historicamente atendidas pela terapia ocupacional, mas com
\end{abstract}

\footnotetext{
${ }^{1}$ Os projetos que basearam a experiência relatada neste artigo foram financiados pelo Ministério da Saúde, por meio dos seguintes programas: (a) Programa Nacional de Reorientação da Formação Profissional em Saúde - Pró-Saúde III; (b) Programa de Educação pelo Trabalho para a Saúde (PET-Saúde); (c) Programa de Educação pelo Trabalho para Saúde- Redes de Atenção à Saúde (PETRedes).

${ }^{2}$ Este manuscrito é fruto de intervençôes, em que se observaram os seguintes aspectos éticos: os projetos que serviram de base para construçáo deste relato de experiência foram autorizados formalmente pelo gestor municipal, bem como pelo gestor do serviço; os resultados foram validados com os membros das equipes de saúde da família, que acompanharam a experiência relatada; e foram omitidos dados que de alguma forma pudessem identificar profissionais ou usuários.
} 
acesso limitado à ABS. Por fim, foi criada uma disciplina obrigatória sobre o tema. As iniciativas do curso de terapia ocupacional se configuraram como resistência a processos de captura dos modos de produçáo do cuidado pela lógica produtivista, insistindo na sensibilização dos atores, na visibilidade a seus modos de saber-fazer alinhados à perspectiva da integralidade, e na articulação da construção de terrenos férteis para a produção de saúde e convivência com e nas diferenças.

Palavras-chave: Educaçáo Continuada, Recursos Humanos em Saúde, Terapia Ocupacional, Atenção Primária à Saúde, Vulnerabilidade em Saúde.

\section{$\underline{\text { Abstract }}$}

Based on the relevance of formation-inducing policies for, with and in the Unified Health System (SUS), this article aims to present the participation of Occupational Therapy undergraduate course of Federal University of Rio de Janeiro in national policies (Pró-Saúde and PET-Saúde), as well as indicate the perspectives and challenges that still exist. It is an experience report about how, with other university courses, the Occupational Therapy course reviewed its curriculum matrix, creating new teaching and learning methodologies that provide professional training ethically committed to SUS and that recognize the strategic role of Primary Care in the ways of thinking and acting in health. In this context, a Basic Health Unit in the vicinity of the University was chosen and started to receive students from six subjects remodeled to promote greater integration between teaching and health service. Extension actions and research projects were also developed, covering populations historically served by Occupational Therapy, but with limited access to primary care. Finally, a compulsory subject on the topic was created. The initiatives of the Occupational Therapy course were configured as resistance to processes in which the productivist logic captures the production of care. Therefore, they sought to raise awareness of the actors, to give visibility to their know-how aligned to the perspective of integrality, and to articulate them in the construction of fertile lands to produce health and living within the differences.

Keywords: Education; Continuing, Health Workforce, Occupational Therapy, Primary Health Care, Health Vulnerability.

\section{Introduçáo}

A legislação brasileira determina a universalidade e a integralidade da atenção à saúde, com o oferecimento de açóes de prevenção, promoção, proteção e reabilitação em todos os níveis de atençâo (Brasil, 1990), bem como determina que a porta de entrada do sistema de saúde é a Atenção Básica - AB (Brasil, 2017). Contudo, a implantação da Rede de Atenção à Saúde (RAS), de acordo com esses princípios, ainda encontra inúmeros desafios, entre os quais se destaca a formação profissional. Verifica-se a necessidade da formação permanente de profissionais para a atuação no Sistema Único de Saúde (SUS), juntamente à mudança na formação de futuros profissionais, preparando-os para atuar nos diversos cenários do sistema de saúde público brasileiro (Ceccim \& Feuerwerker, 2004; Feuerwerker, 2007).

Nesta direção, diversos autores enfatizam que a formação profissional em saúde é ainda um espelho do que se produz na academia e está tradicionalmente focada na doença e na atenção 
especializada, oferecida predominantemente de forma individual e nos níveis hospitalar e ambulatorial. Tal formação não tem preparado os profissionais para a realidade e necessidades da maioria da populaçáo e tem se configurado apartada das demandas complexas e específicas que surgem na $A B$, as quais exigem novas formas de agir, pautadas pela interdisciplinaridade $e$ intersetorialidade com foco nas tecnologias leves de cuidado (Brasil, 2004, 2007; Marsiglia, 2012; Reis et al., 2012; Rocha \& Souza, 2011).

$\mathrm{Na}$ tentativa de reverter esse processo, uma medida importante foi a criação das Diretrizes Curriculares Nacionais (DCN), as quais apontam que a formação profissional na área da saúde deve enfatizar as necessidades do SUS (Brasil, 2002; Marsiglia, 2012). No que se refere às DCN de graduação em terapia ocupacional, por exemplo, estas instituem que a formação do terapeuta ocupacional deve capacitá-lo a participar da atenção integral à saúde da população, com ações de prevenção, promoção, proteção e reabilitação, enfatizando o trabalho em equipe. Tais ações, que podem ocorrer de forma individual ou coletiva, devem acontecer de maneira integrada às demais instâncias do sistema de saúde, considerando-se a sua regionalização e hierarquização (Brasil, 2002).

Outra ação estratégica foi a criação da Secretaria de Gestão do Trabalho e da Educação em Saúde (SGTES), que propiciou a publicação da Portaria Nacional de Educaçáo Permanente em Saúde (PNEPS), em 2004, bem como o desenvolvimento de açóes voltadas para a reorientação da formação profissional, para a valorização da Atenção Básica e para o fortalecimento do SUS. A educação permanente, de caráter interdisciplinar, integra-se ao cotidiano do trabalho e parte das necessidades e situaçóes reais do serviço; envolve açóes que propiciem a aprendizagem significativa e a problematização da prática, visando aperfeiçoar os processos de trabalho e, por conseguinte, aumentar a eficiência do sistema de saúde. Para a sua efetivação, é fundamental a articulação entre as instituiçóes de ensino, os serviços e a comunidade (Brasil, 2018; Miccas \& Batista, 2014).

Neste contexto, a SGTES, por meio de uma parceria entre o Ministério da Saúde, o Ministério da Educação e a Organização Pan-Americana da Saúde/ Organização Mundial da Saúde (OPAS/OMS), lançou, em 2005, o Programa Nacional de Reorientação da Formação Profissional em Saúde (Pró-Saúde); este foi inicialmente voltado para os cursos de Medicina, Enfermagem e Odontologia, mas, posteriormente, foi ampliado para as demais profissóes da saúde (Miccas \& Batista, 2014, p. 13). O Pró-Saúde tem como eixo central a integração ensinoserviço, visando incentivar a transformação da formaçãa profissional, a geração de conhecimento e a prestação de serviços à população, "[...] assegurando uma abordagem integral do processo saúde-doença com ênfase na atenção básica” (Brasil, 2007, p. 17). Ao lado do Pró-Saúde também foi instituído o Programa de Educação pelo Trabalho para a Saúde (PET-Saúde), que tem como pressupostos: a educação pelo trabalho e a atuação profissional pautada pelo espírito crítico, pela cidadania e pela função social da educação superior, orientados pelo princípio da indissociabilidade entre ensino, pesquisa, extensão e serviço (Brasil, 2011).

À vista disso, no final do ano de 2011, foi constituído um fórum para preparar a adesão da Universidade Federal do Rio de Janeiro (UFRJ) ao Pró-Saúde III. O curso de terapia ocupacional vislumbrou contribuir para o alcance de duas importantes metas anteriormente citadas: a formação permanente de profissionais na $\mathrm{AB}$, favorecendo a integração da universidade com a comunidade que a cerca, e a formação acadêmica de forma integrada à realidade da atenção pública à saúde, propiciando a vivência prática do cuidado à população por meio da Estratégia Saúde da Família (ESF).

Diante deste cenário, o objetivo deste artigo é apresentar a experiência da participação do Curso de Graduação em Terapia Ocupacional da UFRJ no Pró-Saúde e no PET-Saúde, bem 
como indicar as perspectivas e desafios que ainda se configuram para o alcance das metas traçadas. A relevância da apresentação dessa experiência reside na possibilidade de fornecer subsídios que alimentem a discussão da formaçáo para, com e no SUS em diálogo com a terapia ocupacional.

\section{Relato da Experiência}

O Curso de Graduação em Terapia Ocupacional da UFRJ foi criado em 2008 pelo Programa de Apoio a Planos de Reestruturação e Expansão das Universidades Federais (Reuni). Tendo em vista que o projeto pedagógico do curso foi desenvolvido de acordo com as DCN, era previsto que a formaçáo dos futuros terapeutas ocupacionais fosse voltada para o SUS. Entretanto, a implantaçáo de uma metodologia de ação sobre este tema ainda era frágil.

Constatou-se, assim, com a implementação do curso, que as disciplinas e ações de pesquisa e extensão ainda eram prioritariamente focadas na média e alta complexidades e nas áreas de especialidades clínicas, com as práticas baseadas nos serviços universitários, com pouca inserção em outros cenários de prática na rede do SUS, em especial na AB. De outro lado, também foram identificados poucos mecanismos de interlocuçáo entre as disciplinas do curso e, mais raros ainda no que se refere ao ensino e à extensão em conjunto com outros cursos de graduação. Destarte, a adesão aos programas Pró-Saúde e PET-Saúde foi uma tentativa de superar essas questóes e promover uma autorreflexão sobre o processo de formação em terapia ocupacional.

\section{Programa Nacional de Reorientação da Formação Profissional em Saúde - Pró-Saúde III no Curso de Terapia Ocupacional da UFRJ}

Com a adesão ao Pró-Saúde III, em 2012, os docentes do curso de terapia ocupacional passaram a se debruçar sobre a sua matriz curricular e a vislumbrar mudanças metodológicas, mantendo a matriz original. Nesse processo, o curso se comprometeu, então, a inserir seis de suas disciplinas obrigatórias nos cenários de prática do SUS. Essa inserção se caracterizava por visitas programadas aos serviços da Área Programática 3.1 (AP 3.1) da cidade de Rio de Janeiro, regiáo situada no entorno do campus.

Concomitantemente ao processo de adesão ao Pró-Saúde III, os doze cursos de saúde da UFRJ submeteram projetos de pesquisa para concorrer ao edital do PET-Saúde, visto que, pela primeira vez, este edital estava atrelado ao Pró-Saúde. Assim, em 2012, o curso de graduação em terapia ocupacional teve um projeto PET-Saúde aprovado, o qual abordou o atendimento de pessoas com deficiência na ESF. No ano seguinte, no âmbito do edital PET-Redes, um segundo projeto abordando a interlocução entre a Rede de Atenção Psicossocial (RAPS) e a AB também foi aprovado.

Diante da jovialidade do curso na universidade, a aprovação dos projetos PET-Saúde e PET-Redes foi reconhecida como exemplo, pois demonstrou que a formação em terapia ocupacional já considerava a construção de perfis profissionais sintonizados aos princípios do SUS, desde o início de sua implementação.

\section{Disciplinas obrigatórias do curso de terapia ocupacional: modulaçóes a partir da adesáo ao Pró-Saúde III}

Conforme preconizado pelas políticas de saúde e pelas políticas indutoras da formação para o SUS, a $A B$ é a estratégia principal para a substituição do modelo tradicional de organização do cuidado em saúde, historicamente centrado na doença e no atendimento hospitalar, assim como 
para a reorientação dos currículos. Além de ser a porta de entrada do sistema, a $\mathrm{AB}$ tem o papel de coordenar o cuidado e se constitui como centro de comunicaçáo da RAS (Brasil, 2007, 2017).

Com base nessa premissa, a $\mathrm{AB}$ foi a principal aposta dos cursos da UFRJ que aderiram ao Pró-Saúde III. Para aproximação da rede, foram mapeadas as Unidades Básicas de Saúde que se localizavam na AP 3.1 e uma equipe de professores visitou os serviços para fazer um levantamento de quais eram os campos mais adequados, considerando a presença de preceptores e espaço físico para receber os estudantes.

Assim, o curso de terapia ocupacional teve como cenário uma unidade de saúde de modelo misto que contava com atendimento ambulatorial e quatro equipes da ESF, além de atendimento especializado em: homeopatia, psicologia, fisioterapia, terapia ocupacional, fonoaudiologia, nutrição, odontologia e serviço social.

Foram pactuadas seis disciplinas que começaram a articular açóes na unidade de saúde, conforme demonstra a Tabela 1. Não obstante as açôes já realizadas, o Núcleo Docente Estruturante (NDE) do curso passou a discutir a necessidade de maior inserção dos estudantes em atividades de acompanhamento da realidade dos serviços do SUS e de sua clientela, em diversos níveis de atenção à saúde, bem como a importância da inclusão do SUS como um tema transversal no currículo.

Tabela 1. Disciplinas do Curso de Graduação em Terapia Ocupacional da UFRJ e suas Ações Relacionadas à Atenção Básica/ Sistema Único de Saúde.

\begin{tabular}{|c|c|}
\hline Disciplinas & Açóes desenvolvidas \\
\hline $\begin{array}{l}\text { Terapia Ocupacional } \\
\text { em Saúde Mental }\end{array}$ & $\begin{array}{l}\text { Realização de visitas domiciliares, junto com as equipes da ESF, em casos de } \\
\text { saúde mental, para que os estudantes conhecessem os processos de trabalho de } \\
\text { equipes da ESF junto aos CAPS (Centros de Atenção Psicossocial), entre } \\
\text { outros serviços e setores. Participação no Evento em Comemoração ao dia } 18 \\
\text { de Maio - Dia da Luta antimanicomial. }\end{array}$ \\
\hline $\begin{array}{l}\text { Terapia Ocupacional, } \\
\text { Antropologia e } \\
\text { Sociologia }\end{array}$ & $\begin{array}{l}\text { Implementação do projeto Feira da Família, voltado para a identificação dos } \\
\text { fazeres locais e de incentivo à economia solidária, que contou com a } \\
\text { participação dos estudantes da disciplina, de bolsistas de extensão e dos } \\
\text { projetos PET-Saúde e PET-Saúde/RAPS. }\end{array}$ \\
\hline $\begin{array}{l}\text { Administração, } \\
\text { Planejamento e Gestão } \\
\text { em Terapia } \\
\text { Ocupacional }\end{array}$ & $\begin{array}{c}\text { Realização de visitas à Unidade de Saúde para que os estudantes conhecessem } \\
\text { processos de trabalho de equipes da ESF e de gestão de uma Unidade Básica } \\
\text { de Saúde (UBS). Contou com profissionais dos serviços como professores } \\
\text { convidados na referida disciplina da UFRJ. }\end{array}$ \\
\hline $\begin{array}{l}\text { Terapia Ocupacional } \\
\text { na Saúde da Criança }\end{array}$ & $\begin{array}{r}\text { Realização de visitas domiciliares e em program } \\
\text { cuidado materno-infa }\end{array}$ \\
\hline $\begin{array}{l}\text { Terapia Ocupacional } \\
\text { Geral }\end{array}$ & $\begin{array}{l}\text { Realização de visitas domiciliares e do serviço de terapia ocupacional da } \\
\text { Unidade para que os estudantes conhecessem os processos de trabalho das } \\
\text { equipes da ESF e do terapeuta ocupacional com diferentes populaçóes. } \\
\text { Participação na organização das atividades do evento Feira da Família. }\end{array}$ \\
\hline $\begin{array}{l}\text { Estágio de Terapia } \\
\text { Ocupacional: Saúde } \\
\text { Mental e Terapia } \\
\text { Ocupacional Social. }\end{array}$ & $\begin{array}{c}\text { Realização de prática de estágio curricular em terapia ocupacional em saúde } \\
\text { mental e terapia ocupacional social, privilegiando as açóes na Atenção Básica e } \\
\text { territoriais. }\end{array}$ \\
\hline
\end{tabular}

Fonte: elaborado pelas autoras.

Além da inserção destas disciplinas nos cenários de prática do SUS, foram implementadas outras iniciativas para fomentar a reorientação da formação, as quais serão apresentadas a seguir. 


\section{Projetos, cursos e eventos de extensáo via Pró-Saúde}

A aproximação do curso com o serviço de saúde permitiu conhecer as necessidades da população atendida pelas equipes da ESF que embasaram o desenvolvimento de três açóes de extensão, apresentadas na Tabela 2.

Tabela 2. Açôes de extensão do curso de terapia ocupacional desenvolvidas no âmbito das políticas indutoras de formação para o SUS.

\begin{tabular}{|c|c|c|}
\hline Título da açáo & Tipo & Objetivos \\
\hline $\begin{array}{l}\text { Formando Tecituras do } \\
\text { Cuidado em Saúde Mental }\end{array}$ & Projeto & $\begin{array}{l}\text { Promover o acesso aos serviços de } \mathrm{AB} \text { das pessoas com } \\
\text { histórias de sofrimento psíquico, transtornos mentais e que } \\
\text { fazem uso prejudicial de álcool e outras drogas, } \\
\text { fomentando, junto com as equipes da ESF, práticas de } \\
\text { acolhimento e construção de Projetos Terapêuticos } \\
\text { Singulares (PTS) com ênfase em trabalhos coletivos, } \\
\text { especialmente oficinas, e integração de açóes entre AB, } \\
\text { CAPS e outros serviços e setores. }\end{array}$ \\
\hline $\begin{array}{c}\text { Arte, Cultura e } \\
\text { Acessibilidade na Atenção } \\
\text { Básica }\end{array}$ & Projeto & $\begin{array}{l}\text { Promover atividades de arte e corpo visando ao } \\
\text { acolhimento e à construção de uma linha de cuidado de } \\
\text { crianças referidas à ESF, e seu acompanhamento junto às } \\
\text { equipes, matriciadores e escola do território. }\end{array}$ \\
\hline $\begin{array}{l}\text { Atenção à saúde da pessoa } \\
\text { com deficiência na } \\
\text { Estratégia Saúde da Família }\end{array}$ & Curso & $\begin{array}{l}\text { Sensibilizar os profissionais da atenção básica quanto ao } \\
\text { acolhimento e ao atendimento de pessoas com deficiência; } \\
\text { capacitá-los na prevenção primária e secundária de } \\
\text { deficiências e no oferecimento de orientações básicas de } \\
\text { reabilitação. }\end{array}$ \\
\hline
\end{tabular}

Fonte: elaborado pelas autoras.

Além das ações de extensão supracitadas, foram realizados, posteriormente, dois novos projetos de extensão integrados aos já existentes: os eventos comunitários "Comemoração ao dia 18 de Maio - Dia da Luta antimanicomial" e a "Feira da Família". Esses eventos ocorreram de forma integrada e concomitante, contando com a participação dos usuários e trabalhadores da UBS, estudantes e professores envolvidos nos projetos de extensão, nos projetos PET-Saúde e nas disciplinas relacionadas às temáticas dos eventos, além dos trabalhadores e usuários de outros serviços da Rede de Atenção Psicossocial (RAPS) e de outros setores.

Foram realizadas oficinas, apresentaçôes artístico-culturais dos usuários da saúde mental da ESF e dos CAPS, apresentação de pôsteres elaborados pelos estudantes das disciplinas e exposição de produtos desenvolvidos pelos usuários da saúde mental da $\mathrm{AB}$ e dos CAPS, integrando de forma singular as açôes da $\mathrm{AB}$ e da RAPS. A Feira da Família consistiu na exposição de produtos feitos por moradores do território de abrangência da ESF, visando tanto à possibilidade de geração de renda quanto ao ensino das técnicas para realização das atividades artesanais. $\mathrm{O}$ evento chegou ao número de 38 expositores cadastrados.

A relevância desses eventos de extensão se mostrou no empoderamento dos sujeitos e das comunidades a partir do reconhecimento e fomento da diversidade da cultura local e da gestão participativa das açóes de saúde-cultura no território. Os eventos tiveram como resultados: fortalecimento de oficinas que já aconteciam na ESF, ampliando sua produção e garantindo acesso a pessoas com sofrimento psíquico e com 
deficiência; sensibilização das equipes da ESF para construção de espaços de promoção de saúde e participação social; geração de renda e qualificação política pela articulação com movimentos sociais.

\section{Os Programas de Educaçáo para o Trabalho em Saúde/PET-Saúde no Curso de Terapia Ocupacional da UFRJ}

O curso de Terapia Ocupacional da UFRJ desenvolveu dois projetos PET-Saúde relacionados com a Educação Permanente, de modo a contribuir tanto com a formação dos estudantes nos cenários reais do SUS quanto com a dos profissionais da Atenção Básica, em especial, os que exerciam papel de preceptores dos estudantes-bolsistas. O trabalho de apoio técnico-pedagógico que os projetos PET-Saúde desenvolviam com as equipes da ESF era voltado para as populaçóes tradicionalmente atendidas pela terapia ocupacional, e que usualmente têm dificuldade de acesso à rede ou, quando o fazem, acessam diretamente serviços de maior complexidade, ficando numa zona de invisibilidade no que diz respeito à $\mathrm{AB}$.

\section{PET-Saúde - Atençáo à saúde da pessoa com deficiência na Estratégia Saúde da Família: discutindo necessidades e novas possibilidades de cuidado}

Este projeto visou promover a integraçáo ensino, serviço e pesquisa no campo das práticas territoriais de cuidado à saúde das pessoas com deficiência, por meio da análise das açóes desenvolvidas pelos profissionais das equipes de saúde da família. A equipe foi composta por: uma tutora (professora do curso de terapia ocupacional); seis preceptores profissionais integrantes das equipes da Estratégia Saúde da Família (ESF) e 20 estudantes do curso de terapia ocupacional que ocuparam as 12 bolsas do PET-Saúde ao longo dos seus 36 meses de duração.

O projeto foi desenvolvido em três etapas, no período de 2012 a 2015. Na primeira etapa, os estudantes tiveram um período de quatro meses para conhecerem os processos de trabalho na ESF. Nessa direção, os estudantes foram divididos em trios, os quais ficaram vinculados às equipes da ESF para imersão em suas açôes cotidianas (Saporito, 2013).

A segunda etapa do projeto, que teve duração de seis meses, teve como intuito mapear a população com deficiência atendida pelas equipes. Como fonte de dados, foram utilizados os registros da ficha de cadastro familiar da área (Ficha A), que alimentam o Sistema de Informação da Atenção Básica (SIAB). A Ficha A foi escolhida como fonte porque é o cadastro familiar que contém dados básicos das características socioeconômicas, de saúde e moradia das famílias e seus indivíduos (Saporito, 2013).

A existência do registro de pelo menos uma pessoa com deficiência, física, mental ou sensorial, foi o critério de inclusão dos registros. Nessa direção, de 3.983 documentos, 216 tinham registro de pessoas com deficiência. A análise desses registros demonstrou que havia inconsistências no preenchimento das fichas no que se referia à pessoa com deficiência, como, por exemplo, pessoas que fazem uso de óculos estavam cadastradas como pessoas com deficiência visual (Saporito, 2013).

A terceira e última etapa do projeto visou analisar casos traçadores que, segundo Tansey (2007), é uma estratégia usada em pesquisas qualitativas para obter informaçóes sobre processos específicos. O uso de casos traçadores se dá a partir da identificaçâo de situaçóes ou 
atores-chave que ilustram de forma mais representativa o fenômeno a ser investigado. Assim, foi solicitado que cada equipe elencasse três casos de pessoas com deficiência considerados de manejo complexo, para que os estudantes acompanhassem o desenvolvimento dos Projetos Terapêuticos Singulares (PTS) relacionados a estes casos.

O resultado dessas três fases da pesquisa foi analisado e evidenciou que o cuidado da pessoa com deficiência na $A B$ é uma via importante para reduzir a inequidade de acesso deste grupo ao sistema de saúde. Para tanto, é preciso difundir entre os profissionais da ESF a possibilidade de construção de PTS pautados na realidade das comunidades e voltados para o aumento da participaçáo social das pessoas com deficiência (Schultz \& Alonso, 2016).

\section{PET-Saúde/Redes: formando tessituras na Saúde da Família}

A partir do Edital PET-Saúde/Redes de 2013, o curso de terapia ocupacional deu início ao projeto de pesquisa-intervenção intitulado "PET-SAÚDE MENTAL: formando tessituras na Saúde da Família”. Este projeto foi desenhado de forma integrada ao projeto de extensão "Formando Tessituras do Cuidado em Saúde Mental", ambos coordenados pela mesma professora no período de 2013 a 2015 . A equipe do PET-SAÚDE MENTAL foi composta por: uma tutora (professora do curso de terapia ocupacional); seis preceptores profissionais integrantes das equipes da Estratégia Saúde da Família (ESF) e do ambulatório do serviço parceiro; 12 bolsistas dos cursos de terapia ocupacional e serviço social, e cinco estudantes voluntárias dos cursos de terapia ocupacional e de dança.

Os projetos PET-Saúde Mental e de extensão foram criados com base na identificação de demanda das equipes da ESF em relação ao cuidado em saúde mental da população adscrita, a qual apontava para uma situação paradoxal: de um lado, alguns trabalhadores diziam náo saber o que fazer com os casos de saúde mental referenciados pelo serviço e, de outro, alguns diziam não existir demanda de atendimento de casos de saúde mental.

Esses projetos buscavam, sobretudo, construir, junto com as equipes de Saúde da Família, novos modos de pensar e agir em saúde mental, promover acesso aos usuários de saúde mental aos serviços de saúde em diferentes níveis de complexidade - em especial, na $\mathrm{AB}$, ampliar a rede intersetorial de cuidado no território, e dar suporte às equipes da ESF para o acompanhamento dos casos, em conjunto com a Assistência Social, Educação, Esporte e Lazer. As etapas da pesquisa foram: a) mapeamento de pessoas com transtornos mentais do território, incluindo os casos de álcool e outras drogas; b) levantamento de atividades culturais e de lazer do território; c) mapeamento dos serviços intersetoriais e de saúde mental da Rede de Atenção Psicossocial (RAPS) do território; d) criação de oficinas junto à ESF para acolhimento de casos de saúde mental.

Como resultado dessa pesquisa-intervenção, foram criadas oficinas envolvendo os trabalhadores da ESF no acompanhamento dos casos de saúde mental, que foram, posteriormente, coordenadas por profissionais do Núcleo de Apoio à Saúde da Família (NASF), implantado no território no início de 2015. Algumas oficinas tiveram maior adesão e perduraram após a finalização do PET-Saúde Mental, como a "Oficina de artesanato das mulheres", voltada para usuárias da ESF com diferentes histórias de sofrimento psíquico e/ ou uso de drogas, e a "Horta da Família". 
A implantação desses dispositivos de cuidado em saúde mental na UBS evidenciou a importância do trabalho integrado entre ensino, serviço, pesquisa e extensão, demonstrando a circularidade do processo. Neste, estudantes de graduação, trabalhadores $\mathrm{da} \mathrm{AB}$ e professores/ pesquisadores da universidade, em proximidade direta com os usuários, aperfeiçoam-se para a construção de práticas efetivas em saúde para a população. Tal processo ressalta a relevância da integraçáo entre universidade, serviço e comunidade.

\section{Resultados Alcançados e Desafios Encontrados}

Os impactos do Pró/PET-Saúde no Curso de Graduação em Terapia Ocupacional da UFRJ destacaram ações dentro e fora da universidade e geraram resultados importantes na reorientação da formação dos estudantes e da assistência na unidade de saúde parceira. Os trabalhos desenvolvidos no âmbito da integração ensino, extensão e pesquisa no serviço fomentaram açóes intersetoriais, envolvendo, além da Estratégia Saúde da Família (ESF), equipamentos da Rede de Atenção Psicossocial (RAPS), da Assistência Social e da Educação, produzindo um deslocamento da função das equipes, de encaminhadores para parceiros no cuidado.

Os profissionais da ESF referiram que os projetos foram uma aposta nas equipes pela incorporaçáo de novas estratégias de cuidado criadas no contato com os estudantes. Assim, a integração ensino-serviço possibilitou uma maior articulação da unidade com a rede, o que já era intenção das equipes, e a parceria com a universidade ajudou a concretizá-la. As políticas indutoras têm sido apontadas, de fato, como importantes contribuições para o fortalecimento da educação interprofissional em saúde (Brasil, 2018).

Os projetos do PET-Saúde e de extensão colocaram em evidência necessidades de saúde das pessoas com deficiência e sofrimento psíquico na $\mathrm{AB}$ a partir do acolhimento em açóes de saúde e cultura no território. Como efeito dos trabalhos desenvolvidos, foi possível articular linhas de cuidado de crianças e adultos em sofrimento psíquico e de pessoas com deficiência e suas famílias na perspectiva da integralidade e do enfrentamento de situaçóes de vulnerabilidade social junto às equipes da ESF.

No que tange à saúde mental, as ações permitiram a ampliação da compreensão do sofrimento psíquico, evidenciando que o acolhimento de casos de saúde mental também deve ser feito no território pelos profissionais da ESF, que passaram a identificar as estratégias já desenvolvidas pelas equipes também como açôes de saúde mental.

No que se refere à população com deficiência, a implementação do PET-Saúde permitiu identificar a necessidade de uma maior aproximação dos profissionais da ESF com a discussáo do cuidado das pessoas com deficiência, de modo a desmistificar que as necessidades em saúde desse grupo populacional estariam ligadas aos centros especializados de reabilitaçáo. Como destaque, o projeto desenvolveu estratégias voltadas para o aumento da participaçáo social das pessoas com deficiência, tendo a ESF um palco privilegiado (Schultz \& Alonso, 2016), a exemplo do trabalho desenvolvido por Rocha \& Kretzer (2009).

Os eventos de extensão possibilitaram dinamizar o debate sobre a loucura e a exclusão social no território, assim como a mobilização das comunidades junto à subprefeitura para modificaçóes no espaço da praça em que foram realizados, visando à acessibilidade de todos, em especial, das pessoas com deficiência. A participação de líderes comunitários, moradores e equipes de saúde na cogestão dos eventos incitou o convite à unidade de saúde parceira para ser unidade modelo de gestão participativa, criando o colegiado gestor da unidade com a participação de um dos usuários do PET-Saúde e um professor do PET- 
Saúde Mental. Tal conquista foi avaliada pela direção da UBS como fruto da parceria com os projetos do curso de terapia ocupacional da UFRJ.

As diferentes iniciativas apresentadas neste artigo têm gerado um crescente número de estudantes interessados pelas áreas $\mathrm{da} A \mathrm{~B}$ e sua interface com os campos da pessoa com deficiência e da saúde mental. A mudança na visão dos estudantes, imersos no contexto do trabalho em saúde, possibilitou compreender que o trabalho do terapeuta ocupacional, em qualquer área ou nível de complexidade, deve ter como princípios a inter ou transdisciplinaridade, a integralidade do cuidado e a responsabilidade territorial da assistência. A participação dos estudantes nas açôes relatadas permitiu a instrumentalização destes para fornecer apoio às equipes e intervençôes de cuidado, considerando os determinantes sociais da saúde, o que coaduna com pressupostos da $\mathrm{AB}$.

Além disso, como resultado de um maior enfoque sobre o tema da $\mathrm{AB}$ e da percepção do colegiado do curso e dos estudantes quanto à necessidade de garantia de um espaço permanente para sua discussão na formação profissional, em 2018, foi iniciada a oferta de uma disciplina obrigatória no curso, denominada Terapia ocupacional na atençáo básica. A criação desta disciplina, somada a uma maior aproximação de disciplinas pré-existentes com a $\mathrm{AB}$ e o desenvolvimento de outros projetos de pesquisa e extensão realizados na rede municipal de saúde, podem ser considerados frutos das políticas indutoras de mudança curricular que se mantêm até os dias atuais. A avaliação do impacto das ações supracitadas a formação dos estudantes é alvo de uma pesquisa em andamento.

Os docentes reconhecem muitas conquistas nesse período de adesão ao Pró-Saúde III, mas ao mesmo tempo percebem desafios a serem superados. Neste sentido, destaca-se a necessidade de ampliar as açôes das disciplinas e fortalecer o diálogo com os professores que não tiveram uma experiência clínica e de formação voltada para o SUS. Diante disso, evidencia-se a importância de dar continuidade à criação de políticas indutoras de mudanças na formação para o SUS, de modo a alinhá-las às políticas de extensão e de pesquisa da universidade, equiparando as açôes no âmbito do Pró/PET-Saúde às demais atividades da carreira docente. Essas problematizaçóes estão implicadas na reforma curricular em curso e subsidiam a criaçáo de novas metodologias de ensino e aprendizagem de forma sustentável e integrada aos serviços de saúde.

No âmbito da universidade, alguns equívocos na organização dos grupos Pró/PETSaúde dificultaram a construção de projetos interdisciplinares, o que não favoreceu a criação de disciplinas comuns nos currículos e a integraçáo entre as açôes dos diferentes cursos. Como consequência, os projetos se desenvolveram intracursos e sua inserção nos serviços se deu de forma independente. Apesar disso, no que diz respeito à formaçáo dos estudantes, estes tiveram oportunidade de participar de açôes interdisciplinares a partir do contato com as equipes da ESF e com estudantes de outras áreas, o que possibilitou a vivência do trabalho em equipe.

No que tange ao curso de terapia ocupacional, dois desafios foram observados: um se refere à visão ainda arraigada na especialidade clínica, o que acarreta ações no Pró-Saúde pautadas no conteúdo das disciplinas com caráter ilustrativo, distante do que é preconizado pelas políticas de indução da orientação dos currículos para o SUS. Sendo assim, as açôes, na maioria das disciplinas, ficaram restritas às visitas pontuais que pouco resultam em benefícios para a comunidade/população, ainda num modelo unidirecional que năo se aproxima da construção compartilhada do conhecimento entre serviço e universidade. 
No que diz respeito aos serviços de saúde, os desafios encontrados se referem aos modos de gestâo impostos aos serviços, que vêm se configurando pautados por caminhos excessivamente burocráticos, que privilegiam uma visão da produtividade avaliada por número de procedimentos. Este modo de organizar o trabalho na ESF interfere na disponibilidade dos trabalhadores de se envolverem nas açôes de promoçáo de saúde, na coordenaçáo do cuidado na RAS e no estímulo ao controle social, também previstos na Política Nacional de Atenção Básica (Brasil, 2017). Além disso, a falta de comprometimento na visão dos profissionais é reflexo das diferenças nas atribuiçóes e gratificaçóes dadas aos membros da equipe. Em especial, os agentes comunitários em saúde demandaram reconhecimento do seu envolvimento nas açóes Pró/PET com a possibilidade de serem arrolados como preceptores.

Miccas \& Batista (2014) apontam a necessidade de manutenção de políticas públicas que fomentem a educação permanente em saúde e a articulação com as instituições de ensino, bem como a disponibilizaçáo de recursos financeiros e humanos para este fim. Contudo, observa-se um enfraquecimento dos programas que possuem este objetivo, a exemplo da redução dos recursos destinados ao Pró/PET Saúde nas suas últimas ediçóes.

Outro fator que caminha na contramão dos esforços para o fortalecimento da $\mathrm{AB}$ e da formação no e para o SUS é a crise na saúde no Município do Rio de Janeiro, que ocorreu a partir de 2018. Neste cenário, houve uma grande redução no número de equipes de saúde da família, com o consequente aumento da proporção entre usuários e equipes, o que evidenciou uma crescente ênfase na produtividade e a fragilidade dos vínculos empregatícios por meio de Organizaçōes Sociais de Saúde (Melo et al., 2019). Tais fatos não trazem implicaçôes apenas para o cotidiano dos serviços, mas também para as instituiçôes de ensino, que se deparam com novos desafios para a formação profissional em saúde, diante de um contexto de maior precarização da assistência e de desvalorização dos trabalhadores, de seus saberes e de sua reflexão sobre a prática.

\section{Conclusáo}

As iniciativas do curso de terapia ocupacional junto ao Pró/PET-Saúde se configuraram como resistência a processos de engessamento e captura dos modos de produçáo do cuidado pela lógica produtivista, insistindo na sensibilização dos atores para dar visibilidade a seus modos de saber-fazer alinhados à perspectiva do acolhimento e da integralidade, e articulálos na construção de terrenos férteis para a produção de saúde e convivência com e nas diferenças. As açóes desenvolvidas possibilitaram a articulaçáo e a formaçấo conjunta de profissionais, professores e estudantes, favorecendo mudanças no currículo no sentido de uma maior aproximação com a Atençáo Básica à Saúde. Observa-se, assim, a importância das políticas indutoras de mudanças curriculares e de açóes que visem à articulação entre o ensino, os serviços e a comunidade, para o fortalecimento do SUS e a transformação das práticas em saúde.

\section{Referências}

Brasil. (1990). Lei no 8.080, de 19 de setembro de 1990. Dispóe sobre as condiçóes para a promoção, proteção e recuperação da saúde, a organização e funcionamento dos serviços correspondentes e dá outras providências. Diário Oficial [da] República Federativa do Brasil, Brasília. 
Brasil. (2002). Resolução CNE/CES no 6, de 19 de fevereiro de 2002. Institui as Diretrizes Curriculares Nacionais para cursos de graduação em Terapia Ocupacional. Diário Oficial [da] República Federativa do Brasil, Brasília.

Brasil. (2004). Aprender SUS: O SUS e os cursos de graduação da área de saúde. Brasília: Ministério da Saúde.

Brasil. (2011). Edital no 24, de 15 de dezembro de 2011. Seleção de projetos de instituiçóes de ensino superior no âmbito do Programa Nacional de Reorientação da Formação Profissional em Saúde (PróSaúde) articulado ao Programa de Educação pelo Trabalho para a Saúde - PET-Saúde. Diário Oficial [da] República Federativa do Brasil, Brasília.

Brasil. (2007). Programa Nacional de Reorientação da Formação Profissional em Saúde - Pró-Saúde: objetivos, implementação e desenvolvimento potencial. Brasília: Ministério da Saúde.

Brasil. (2017). Portaria no 2.436, de 21 de setembro de 2017. Aprova a Política Nacional de Atenção Básica, estabelecendo a revisão de diretrizes para a organização da Atenção Básica, no âmbito do Sistema Único de Saúde (SUS). Diário Oficial [da] República Federativa do Brasil, Brasília.

Brasil. (2018). Política Nacional de Educação Permanente em Saúde: o que se tem produzido para o seu fortalecimento? Brasília: Ministério da Saúde.

Ceccim, R. B., \& Feuerwerker, L. C. M. (2004). Mudança na graduação das profissões de saúde sob o eixo da integralidade. Cadernos de Saúde Pública, 20(5), 1400-1410.

Feuerwerker, L. C. M. (2007). Educaçâo na saúde: educação dos profissionais de saúde - um campo de saber e de práticas sociais em construção. Revista Brasileira de Educação Médica, 31(1), 3-4.

Marsiglia, R. M. G. (2012). Universalização do acesso ao Sistema Único de Saúde no Brasil: desafios para a Atenção Primária à Saúde. Cadernos Brasileiros de Terapia Ocupacional, 20(3), 317-325.

Melo, E. A., Mendonça, M. H. M., \& Teixeira, M. (2019). A crise econômica e a atenção primária à saúde no SUS da cidade do Rio de Janeiro, Brasil. Ciência \& Saúde Coletiva, 24(12), 4593-4598.

Miccas, F. L., \& Batista, S. H. S. S. (2014). Educação permanente em saúde: metassíntese. Revista de Saúde Pública, 48(1), 170-185.

Reis, F., Gomes, M. L., \& Aoki, M. (2012). Terapia ocupacional na atenção primária à saúde: reflexóes sobre as populaçôes atendidas. Cadernos Brasileiros de Terapia Ocupacional, 20(3), 341-350.

Rocha, E. F., \& Kretzer, M. R. (2009). Ações de reabilitação de pessoas com deficiência na estratégia da saúde da família da Fundação Zerbini e Secretaria Municipal de Saúde de São Paulo-Região SudesteSapopemba/Vila Prudente-período 2000/2006. Revista de Terapia Ocupacional da Universidade de São Paulo, 20(1), 59-67.

Rocha, E. F., \& Souza, C. C. B. X. (2011). Terapia ocupacional em reabilitação na atenção primária à saúde: possibilidades e desafios. Revista de Terapia Ocupacional da Universidade de São Paulo, 22(1), 36-44.

Saporito, B. E. (2013) Consideraçôes Sobre o Registro de cuidado de pessoas com deficiência em uma UBS: discutindo possibilidades e açôes da Terapia Ocupacional (Trabalho de Conclusão de Curso). Universidade Federal do Rio de Janeiro, Rio de Janeiro.

Schultz, T. G., \& Alonso, C. M. C. (2016). Cuidado da criança com deficiência na Atenção Primária à Saúde. Cadernos de Terapia Ocupacional da UFSCar, 24(3), 611-619.

Tansey, O. (2007). Process tracing and elite interviewing: a case for non-probability sampling. PS: Political Science \& Politics, 40(4), 765-772.

\section{Contribuiçáo dos Autores}

Carolina Maria do Carmo Alonso, Ana Paula Martins

Cazeiro, Marcia Cabral da Costa e Renata Caruso Mecca

participaram ao menos de uma das açóes narradas neste

artigo, bem como contribuíram na elaboração e revisão do

texto, sob a coordenaçáo de Carolina Maria do Carmo

Alonso. Todas as autoras aprovaram a versão final do artigo. 


\section{Autor para correspondência}

Carolina Maria do Carmo Alonso

E-mail: carolmaria1@gmail.com

\section{Editora de seção}

Profa. Dra. Daniela Tavares Gontijo 